\title{
Combined immunodeficiency due to STK4 deficiency
}

INSERM

\section{Source}

INSERM. (1999). Orphanet: an online rare disease and orphan drug data base. Combined immunodeficiency due to STK4 deficiency. ORPHA:314689

Combined immunodeficiency due to ST K4 deficiency is a rare, genetic combined T and B cell immunodeficiency characterized by T - and B-cell lymphopenia,

hypergammag lobulinemia and intermittent neutropenia. It presents with recurrent opportunistic viral, bacterial and fung al infections involving skin (cutaneous papillomatosis, molluscum contagiosum, skin abscesses, mucocutaneous candidiasis), upper and lower respiratory tract or septicemia. Other clinical features include autoimmune manifestations (autoimmune hemolytic anemia) and congenital heart defects (atrial septal defects, patent foramen ovale, mitral, triscupid and pulmonary valve insufficiency). 